\title{
Front Matter: Volume 11127
}

, "Front Matter: Volume 11127," Proc. SPIE 11127, Earth Observing Systems XXIV, 1112701 (14 October 2019); doi: 10.1117/12.2551558

SPIE Event: SPIE Optical Engineering + Applications, 2019, San Diego, California, SPIE. United States 


\section{PROCEEDINGS OF SPIE}

\section{Earth Observing Systems XXIV}

James J. Butler

Xiaoxiong (Jack) Xiong

Xingfa Gu

Editors

11-15 August 2019

San Diego, California, United States

Sponsored and Published by

SPIE 
The papers in this volume were part of the technical conference cited on the cover and title page. Papers were selected and subject to review by the editors and conference program committee. Some conference presentations may not be available for publication. Additional papers and presentation recordings may be available online in the SPIE Digital Library at SPIEDigitalLibrary.org.

The papers reflect the work and thoughts of the authors and are published herein as submitted. The publisher is not responsible for the validity of the information or for any outcomes resulting from reliance thereon.

Please use the following format to cite material from these proceedings:

Author(s), "Title of Paper," in Earth Observing Systems XXIV, edited by James J. Butler, Xiaoxiong (Jack) Xiong, Xingfa GU, Proceedings of SPIE Vol. 11127 (SPIE, Bellingham, WA, 2019) Seven-digit Article CID Number.

ISSN: 0277-786X

ISSN: 1996-756X (electronic)

ISBN: 9781510629479

ISBN: 9781510629486 (electronic)

Published by

SPIE

P.O. Box 10, Bellingham, Washington 98227-0010 USA

Telephone +1 3606763290 (Pacific Time) · Fax +1 3606471445

SPIE.org

Copyright (c) 2019, Society of Photo-Optical Instrumentation Engineers.

Copying of material in this book for internal or personal use, or for the internal or personal use of specific clients, beyond the fair use provisions granted by the U.S. Copyright Law is authorized by SPIE subject to payment of copying fees. The Transactional Reporting Service base fee for this volume is $\$ 21.00$ per article (or portion thereof), which should be paid directly to the Copyright Clearance Center (CCC), 222 Rosewood Drive, Danvers, MA 01923. Payment may also be made electronically through CCC Online at copyright.com. Other copying for republication, resale, advertising or promotion, or any form of systematic or multiple reproduction of any material in this book is prohibited except with permission in writing from the publisher. The CCC fee code is 0277$786 \mathrm{X} / 19 / \$ 21.00$.

Printed in the United States of America by Curran Associates, Inc., under license from SPIE.

Publication of record for individual papers is online in the SPIE Digital Library.

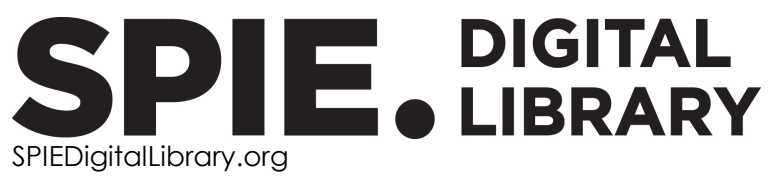

Paper Numbering: Proceedings of SPIE follow an e-First publication model. A unique citation identifier (CID) number is assigned to each article at the time of publication. Utilization of CIDs allows articles to be fully citable as soon as they are published online, and connects the same identifier to all online and print versions of the publication. SPIE uses a seven-digit CID article numbering system structured as follows:

- The first five digits correspond to the SPIE volume number.

- The last two digits indicate publication order within the volume using a Base 36 numbering system employing both numerals and letters. These two-number sets start with $00,01,02,03,04$, 05, 06, 07, 08, 09, OA, OB ... 0Z, followed by 10-1Z, 20-2Z, etc. The CID Number appears on each page of the manuscript. 


\section{Contents}

$\begin{array}{ll}\text { ix } & \text { Authors } \\ \text { xi } & \text { Conference Committee }\end{array}$

SPECIAL SESSION ON AI AND BIG DATA FOR REMOTE SENSING RESEARCH AND APPLICATIONS I

1112706 Application of satellite data assimilation in monitoring the atmospheric duct [11127-4]

SPECIAL SESSION ON AI AND BIG DATA FOR REMOTE SENSING RESEARCH AND APPLICATIONS II

1112707 Synthesis of multi-sensor top of atmosphere and ground level reflectances to support high-resolution AOD estimation with machine learning (Invited Paper) [1 $1127-5]$

1112708 Geospatial object detection using deep networks [1 1127-6]

PRELAUNCH CALIBRATION AND CHARACTERIZATION I

11127 OA Detector based calibration of a portable imaging spectrometer for CLARREO Pathfinder Mission [1 $11127-9]$

$11127 \mathrm{OB} \quad$ The Operational Land Imager-2: prelaunch spectral characterization [11127-10]

11127 OD JPSS-2 VIIRS version 2 at-launch relative spectral response characterization [11127-12]

11127 OE Solar attenuation screen transmittance, modulation, and albedo for JPSS J2 [11127-13]

11127 OF Characterization of JPSS J3 and J4 blackbody emissivity [1 $11127-14]$

PRELAUNCH CALIBRATION AND CHARACTERIZATION II

$11127 \mathrm{OH} \quad$ Spectralon Solar Diffuser BRDF extrapolation to 2.25 microns for JPSS J1, J2, and J3 [1 $1127-16]$

$11127 \mathrm{Ol} \quad$ Understanding optical changes in on-orbit spacecraft materials [1 $11127-17]$

11127 OJ Status of the next generation CMOS-TDI detector for high-resolution imaging [1 $1127-18]$ 
11127 OK Time resolved irradiance of an integrating sphere illuminated by a mode-locked optical parametric oscillator [1 $1127-19]$

\section{DATA ANALYSIS AND MODELING}

$111270 \mathrm{M}$ Straylight physical model and simulator for a rapid and flexible evaluation of impacts on the products derived from the EPS-SG/3MI instrument [1 $11127-21]$

\section{INSTRUMENT INTERCOMPARISONS}

11127 OR On-orbit calibration performance of Sentinel-3A OLCI referencing to SNPP VIIRS: 2-year result [11127-26]

11127 OS Geo-Leo intercalibration to evaluate the radiometric performance of NOAA-20 VIIRS and GOES-16 ABI [ $111127-27]$

11127 OT Assessment of GOES-16/ABI middle wave infrared band using references of Himawari-8/AHI and Aqua/MODIS [1 $11127-28]$

\section{CURRENT AND FUTURE MISSIONS AND INSTRUMENTS}

11127 OW The compact hyperspectral prism spectrometer for sustainable land imaging: enhancing capabilities for land remote sensing [1 $11127-32]$

11127 OX Continuation of the Landsat Mission with Sustained Land Imaging (SLI) and the Reduced Envelope Multispectral Imager (REMI) [1 $11127-33]$

11127 OY Enabling continuity of the Earth radiation budget climate data record using the Clouds and Earth's Radiant Energy System (CERES) Flight Model 5 on S-NPP [1 $11127-34]$

$11127 \mathrm{OZ}$ Study on the feasibility of micro camera systems for asynchronous, gigantic satellite constellation [1 $11127-35]$

\section{ACTIVE REMOTE SENSING: LIDAR AND RADAR}

1112711 Comparison and research of group refractivity models and atmospheric delay to LiDAR [1 11 1 27-37]

1112712 An elevation correction method for colored point cloud in building areas [11127-38] 


\section{ON-ORBIT INSTRUMENT PERFORMANCE}

1112714 Terra MODIS: 20 years of on-orbit calibration and performance (Invited Paper) [11127-40]

1112715 Thirty-six combined years of MODIS geolocation trending [11127-41]

1112716 Performance trends of Clouds and the Earth's Radiant Energy System (CERES) instruments aboard terra, aqua, S-NPP and NOAA-20 missions [1 $11127-42]$

1112717 Checking AIRS nonlinearity in flight [1 $1127-43]$

$1112718 \quad$ AIRS version 6.6 and version 7 level-1C products [1 $1127-44]$

\section{ON-ORBIT INSTRUMENT CALIBRATION AND CHARACTERIZATION I}

11127 1A The NASA OBPG 2020 on-orbit calibration of SNPP VIIRS for ocean color applications [11127-46]

11127 1B Status of NOAA-20 Ozone Monitoring Profiler Suite (OMPS) sensor data calibration and evaluation [1 $11127-47]$

11127 1C Radiometric calibration performance of GOES-17 Advanced Baseline Imager (ABI) [1 $1127-48]$

11127 1D GOES-16 and GOES-17 ABI INR assessment [1 $1127-49]$

\section{ON-ORBIT INSTRUMENT CALIBRATION AND CHARACTERIZATION II}

11127 1E Evaluating crosstalk-induced radiometric deviations in Terra MODIS Band 29, 31, and 32 [1 $1127-50]$

$111271 G$ On gain transition discontinuity in VIIRS on-orbit calibration [1 $1127-52]$

\section{VICARIOUS CALIBRATION I}

$111271 \mathrm{H} \quad$ Advances in utilizing tropical deep convective clouds as a stable target for on-orbit calibration of satellite imager reflective solar bands [1 $1127-53]$

$1112711 \quad$ Using deep convective clouds identified in 16 years of AIRS infrared data for the absolute calibration and stability evaluation of the AIRS 0.4 to 1.0 micron reflected light channels [1 11 127-54]

$111271 \mathrm{~J} \quad$ Assessment of MODIS TEB calibration performance using deep convective clouds [11127-55] 
$111271 \mathrm{~L} \quad$ Field calibration techniques used to characterize the radiometric stability of the GEO-CAPE Airborne Simulator (GCAS) [1 $1127-57]$

$111271 \mathrm{M}$ Solar reflection band site automatic calibration by the Dunhuang site automatic observation radiometric calibration operational system [1 $11127-59]$

11127 1N Intercomparison of the GOES-16 and -17 Advanced Baseline Imager with low-Earth orbit sensors [1 $1127-60]$

$1112710 \quad$ Uncertainty analysis of vicarious radiometric calibration of optical sensor using a Monte Carlo statistical approach [1 $11127-61]$

\section{MODIS AND VIIRS SOLAR DIFFUSER PERFORMANCE}

11127 IP NOAA-20 VIIRS screen transmittance functions determined with both yaw maneuver and regular on-orbit data [1 $11127-62]$

$111271 Q$ Determination of the solar angular dependence of the NOAA-20 VIIRS solar diffuser BRDF change factor [1 $11127-63]$

11127 1R Physical modeling of NOAA-20 VIIRS solar diffuser stability monitor sun view screen transmittance [1 $11127-64]$

11127 iS Modeling spectral degradation of MODIS and VIIRS solar diffusers [1 $1127-65]$

VIIRS DAY/NIGHT BAND PERFORMANCE

$111271 \mathrm{~T} \quad$ Correction of detector nonlinearity induced striping in VIIRS day/night band nighttime imagery [1 $11127-66]$

$111271 \mathrm{R} \quad$ Reprocessing of S-NPP VIIRS DNB detector gains and dark offsets [ $11127-67]$

11127 IV NOAA-20 VIIRS DNB straylight analysis and calibration before/after cryo-cooler door opening [1 $11127-68]$

11127 IW VIIRS DNB time-dependent stray light correction [11127-69]

\section{ON-ORBIT CALIBRATION AND CHARACTERIZATION USING THE MOON AND STARS}

$111271 \mathrm{X} \quad$ Electronic crosstalk characterization and correction for MODIS bands 1 and 2 using lunar observations [ $111127-70]$ 
$111271 Y$ Modulation transfer function characterization for GOES-16 advanced baseline imager using lunar observations [1 $11127-71]$

1112712 NOAA-20 VIIRS initial on-orbit radiometric calibration using scheduled lunar observations [11 $1127-72]$

1112720 PLEIADES high resolution optical sensors radiometric and spatial calibration based on stars [11127-73]

\section{POSTER SESSION}

1112722 Verification and analysis of passive microwave snow depth retrieve algorithm based on snow survey data in China [1 $11127-74]$

1112723 Research on crop classification in Northeast China based on deep learning for Sentinel-2 data [11 $1127-75]$

1112724 Snow water equivalent retrieval algorithm in Jilin Province of China based on multi-temporal Sentinel-1 data [1 $11127-76]$

1112725 Classification of forest vegetation types in Jilin Province, China based on deep learning and multi-temporal Sentinel-2 data [1 $11127-77]$

1112726 Inverse solution to the electronic crosstalk correction of bands 27-30 in Terra MODIS [1 $1127-78$ ]

1112727 Modeling transmittance of MODIS solar diffuser stability monitor sun view screen [1 $1127-79]$

1112728 Comparison of MODIS solar diffuser stability monitor calibration results for different operational configurations [1 $11127-80]$

$111272 \mathrm{~A}$ The continual evaluation of NOAA-20 VIIRS RSB radiometric performance using intercomparison with Aqua MODIS [1 11 127-82]

$111272 \mathrm{~B}$ Lunar calibration and performance assessments of the NOAA-20 VIIRS reflective solar bands [11 $1127-83]$

$111272 \mathrm{C}$ Graphene foils for neutral atom detectors [11127-84]

$111272 \mathrm{D}$ Flexible tuning concept for fiber-integrated lasers featuring multi-wavelength emission with fast switching speeds for DIAL [ $111127-86]$

$111272 \mathrm{E}$ Multi-scale approach to quantify the influence of urban green spaces on urban climate [1 $1127-87]$ 
Proc. of SPIE Vol. $111271112701-8$

Downloaded From: https://www.spiedigitallibrary.org/conference-proceedings-of-spie on 26 Apr 2023 Terms of Use: https://www.spiedigitallibrary.org/terms-of-use 


\section{Authors}

Numbers in the index correspond to the last two digits of the seven-digit citation identifier (CID) article numbering system used in Proceedings of SPIE. The first five digits reflect the volume number. Base 36 numbering is employed for the last two digits and indicates the order of articles within the volume. Numbers start with 00, 01, 02, 03, 04, 05, 06, 07, 08, 09, 0A, 0B...0Z, followed by 10-12, 20-2Z, etc.

Alatan, A. Aydin, 08

Aldoretta, Emily, 14

Anderson, Nikolaus J., $1 \mathrm{~N}$

Angal, Amit, 0A, 14, 1S, 28, 2B

Arellano, Blanca, 2E

Arrowsmith, Alan, 2C

Aumann, Hartmut H., 17, 18, 11

Ayers, Travis, 2C

Aytac, Yigit, OA

Ba, Xiutian, 1M

Baer, James, OW

Bai, Kaixu, 07

Bailey, Sean W., 1 A

Barsi, Julia A., OB

Bartelt, Hartmut, 2D

Barut, Onur, 08

Beck, Trevor, 1B

Becker, Martin, 2D

Bhatt, Rajendra, $1 \mathrm{H}$

Blanchet, Gwendoline, 20

Blonski, Slawomir, 1R, 1T, 1 Z

Broberg, Steven E., 17, 11

Canestri, Alessio, OM

Cao, Changyong, OS, 1R, 1S, 1T, 12

Chang, Ni-Bin, 07

Chang, Tiejun, OT, 14, $1 \mathrm{~J}$

Chen, Hongda, 1U, 1V, 1W, 28, 2B

Chen, Jiuying, 11, 12

Chen, Lin, IM

Chiang, Kwofu, IU, IV, IW

Choi, Taeyoung, 1R, 1S, 12

Choi, Youngwan, $\mathrm{OZ}$

Chu, Mike, OR, 1E, 2A

Cole, Jerold, ow

Cowardin, Heather M., OI

Coyle, Laura, OW

Czapla-Myers, Jeffrey S., iN

Dellomo, John J., 15, 1D

Doelling, David R., 1H

Donley, Eric, OB

Eckardt, Andreas, $0 \mathrm{~J}$

Engelhart, Daniel P., Ol

Eplee, Robert E., Jr., 1 A

Farris, Betsy, OW, OX

Ferguson, Dale C., 이

Fougnie, Bertrand, OM

Fox, Jonathan R., OW, OX

Franz, Bryan A., 1 A

Gao, Caixia, 10
Gao, Wei, 07

Geng, XU, 14, 1W, 2B

Glaesener, Stefan, 0J

Good, William S., OW, OX

Gopalan, Arun, $1 \mathrm{H}$

Grochocki, Frank, OW

Grove, David, 2C

Gu, Lingjia, 22, 23, 24, 25

Gu, Yalong, $1 T$

Guan, Hongcan, 12

Gusev, Sergey, $1 \mathrm{U}$

Gutierrez, Homero, OX

Haney, Conor O., $1 \mathrm{H}$

$\mathrm{Hao}$, Xiaojing, 06

He, Fachuan, 22, 23, 24, 25

Hess, P. C., 16

Hoffmann, Ryan C., Ol

Howell, James, OW, OX

$\mathrm{Hu}$, Jian, 11

Huang, Allen Hung-Lung, 06

Jäger, Matthias, 2D

Jah, Moriba K., Ol

Janz, Scott J., $1 \mathrm{~L}$

Ji, Qiang, $1 G$

Johnson, Lindsay, OE

Kampe, Thomas U., OW, OX

Kaptchen, Paul, OW, OX

Kelbert, Arnaud, 20

Klein, Staci, OE, OH

Kloepfer, Jeremiah, OF

Kowalewski, Matthew G., $1 \mathrm{~L}$

Kuljis, Daniel, OF

Lacan, Antoine, OM

Lasnik, James, OW

Latry, Christophe, 20

Lei, Ning, 1P, 1Q

Leisso, Nathan, OW, OX

Li, Chuanrong, 11, 12, 10

Li, Wei, 12

Li, Xiu, 11

Li, Yanqiu, $1 \mathrm{M}$

Li, Yuan, $1 M$

Lin, Guoqing (Gary), 15

Link, Dan, 14

Liv, He, 25

Liu, Tung-Chang, 1R, 1S, 27

Liu, Yan-An, 06

Liv, Yaokai, 10

Lopez, Heidi, 2C 
LU, Qi, 11

Ma, Lian, 12

Ma, Lingling, 10

Manning, Evan M., 17, 18, 11

Marbach, Thierry, OM

Marca, Sébastien, $O M$

Markham, Brian L., OB

McAndrew, Brendan, OA, OB, OK

McCorkel, Joel, OB, OD, OK

Mclntire, Jeff, OD

Meister, Gerhard, 1A

Meygret, Aimé, 20

Miller, Benjamin G., 01

Moeller, Chris, OD

Morland, Eric, OB

Moyer, David, OD

Mrkvicka, Emily, OW, OX

Murgai, Vijay, OE, OF, $\mathrm{OH}$

Nicks, Dennis, OX

Oudrari, H., IV

Overoye, K., 11

Pagano, Thomas S., 17

Pan, Chunhui, 1B

Pantina, Peter, $1 \mathrm{~L}$

Patt, Frederick S., IA

Paul, Brett, 2C

Pharr, James, OB

Plis, Elena A., 01

Priestley, Kory J., OY, 16

Primus, Chris, $2 \mathrm{C}$

Pulaski, Nick, OX

Qian, Haifeng, $1 \mathrm{C}$

Ren, Ruizhi, 22, 23, 24, 25

Reth, Alan, 1D

Reulke, Ralf, oJ

Reyes, Jacqueline A., 01

Roca, Josep, 2E

Rodriguez, Michael, OB

Rong, Zhiguo, $1 \mathrm{M}$

Rothhardt, Manfred, 2D

Ruppert, Lyle, OW, OX

Salomonson, Vincent, 14

Scarino, Benjamin R., 1H

Schwarting, Thomas, OD, 1G, 1U, IW

Schweickart, Rusty, OW

Sengebusch, Karsten, 0J

Shankar, Mohan, OY, 16

Shao, Xi, OS, 1C, 1R, 1S, 1T, 1Z, 27

Showalter, Nathan, OW, OX

Shrestha, Ashish, 1J

Shuman, Timothy M., OA, OB

Slusher, Robert, OW, OX

Smith, N. P., 16

Smith, Nitchie M., OY, 16

Smith, Ryan, 2C

Solander, Kyle, OW, OX

Strow, L. Larrabee, 18

Sun, Chengbo, 1U, 1V, 1W

Sun, Ling, $1 \mathrm{M}$

Sushkov, Andrei, OB
Szewczyk, Z. P., 16

Tan, Bin, 15, 1D

Tang, Lingli, 10

Teng, Geer, 11, 12

Thomas, Susan, OY, 16

Thome, Kurt, OA

Tiess, Tobias, 2D

Tilton, James C., 15

Turpie, Kevin R., 1 A

Twedt, Kevin A., 14, 28

Uprety, Sirish, OS, 1R, 1T, 12

Walikainen, Dale, OY, 16

Wang, Menghua, OR, 2A

Wang, Ning, 10

Wang, Wenhui, 1T, $1 \mathrm{Z}$

Wang, Zhipeng, 1C

Warden, Robert, OW, OX

Wei, Wei, $1 \mathrm{M}$

Wei, Xiaoli, 07

Wei, Yanlin, 22

Wenny, Brian N., OA

Wieland Shields, Monika, 2C

Wilkinson, Erik, OX

Wilson, R. S., 16

Wilson, Truman, 1X, 1Y, 26, 2B

Wolfe, Robert E., 15, 1D

Wu, Aisheng, 14

Wu, Xiangqian, $1 \mathrm{C}$

Xiong, Sanxiong, $1 \mathrm{~L}$

Xiong, Xiaoxiong (Jack), 0T, 14, 1G, 1 J, 1P, 1Q,

$1 S, 1 \mathrm{U}, 1 \mathrm{~V}, 1 \mathrm{~W}, 1 \mathrm{X}, 1 \mathrm{Y}, 26,27,28,2 \mathrm{~B}$

Xiong, Xiaozhen, 1B

Yang, Shuting, 23

Yoo, Hyelim, 1C

Yu, Fangfang, $1 \mathrm{C}$

Zeiger, Benjamin R., $2 C$

Zender, Bernd, 0J

Zhang, Bin, $1 \mathrm{R}$

Zhang, Huijing, 11, 12

Zhang, Lijun, $1 \mathrm{M}$

Zhang, Ping, 15

Zhang, Yanna, $1 \mathrm{M}$

Zhang, Yixing, 06

Zhang, Yong, $1 \mathrm{M}$

Zhao, Yonggang, 10

Zhou, Mei, 11, 12

Zhu, Xiaoxin, 24

Zukowski, Barbara, OB 


\title{
Conference Committee
}

\author{
Program Track Chair
}

Allen H.-L. Huang, University of Wisconsin-Madison (United States)

Conference Chairs

James J. Butler, NASA Goddard Space Flight Center (United States)

Xiaoxiong (Jack) Xiong, NASA Goddard Space Flight Center

(United States)

Xingfa Gu, Institute of Remote Sensing Applications (China)

Conference Program Committee

Philip E. Ardanuy, Innovim, LLC (United States)

Jeffrey S. Czapla-Myers, James C. Wyant College of Optical

Sciences, The University of Arizona (United States)

Armin Doerry, Sandia National Laboratories (United States)

Christopher N. Durell, Labsphere, Inc. (United States)

Bertrand Fougnie, EUMETSAT (Germany)

Dennis L. Helder, South Dakota State University (United States)

Joel McCorkel, NASA Goddard Space Flight Center (United States)

Vijay Murgai, Raytheon Space and Airborne Systems (United States)

Thomas S. Pagano, Jet Propulsion Laboratory (United States)

Jeffery J. Puschell, Raytheon Space \& Airborne Systems

(United States)

Mark A. Schwarz, SAIC (United States)

\section{Session Chairs}

1 Special Session on Al and Big Data for Remote Sensing Research and Applications I

Jun Li, University of Wisconsin-Madison (United States)

Hung-Lung Allen Huang, University of Wisconsin-Madison

(United States)

2 Special Session on Al and Big Data for Remote Sensing Research and Applications II

Jun Li, University of Wisconsin-Madison (United States)

Hung-Lung Allen Huang, University of Wisconsin-Madison

(United States)

3 Prelaunch Calibration and Characterization I

James J. Butler, NASA Goddard Space Flight Center (United States) 
4 Prelaunch Calibration and Characterization II

Jeffrey S. Czapla-Myers, James C. Wyant College of Optical Sciences, The University of Arizona (United States)

5 Data Analysis and Modeling

Xingfa Gu, Institute of Remote Sensing and Digital Earth, CAS (China)

6 Instrument Intercomparisons

Armin W. Doerry, Sandia National Laboratories (United States)

7 Current and Future Missions and Instruments

Jeffery J. Puschell, Raytheon Space and Airborne Systems (United States)

8 Active Remote Sensing: LIDAR and RADAR

James J. Butler, NASA Goddard Space Flight Center (United States)

9 On-orbit Instrument Performance

Bertrand Fougnie, EUMETSAT (Germany)

10 On-orbit Instrument Calibration and Characterization I

Joel T. McCorkel, NASA Goddard Space Flight Center (United States)

11 On-orbit Instrument Calibration and Characterization II

Xiaoxiong (Jack) Xiong, NASA Goddard Space Flight Center (United States)

12 Vicarious Calibration I

Amit Angal, Science Systems and Applications, Inc. (United States)

13 Vicarious Calibration II

Thomas S. Pagano, Jet Propulsion Laboratory (United States)

14 MODIS and VIIRS Solar Diffuser Performance

Christopher N. Durell, Labsphere, Inc. (United States)

15 VIIRS Day/Night Band Performance

Vijay Murgai, Raytheon Space and Airborne Systems (United States)

16 On-orbit Calibration and Characterization Using the Moon and Stars James J. Butler, NASA Goddard Space Flight Center (United States) 